\title{
Pela possibilidade do uso de novas metáforas na pesquisa transcultural - menos distância e mais fricção
}

\author{
For the possibility of using new metaphors on cross-cultural research - less \\ distance and more friction
}

Ana Celano ${ }^{1}$

Ana Lucia Guedes ${ }^{2}$

\section{Resumo}

A metáfora da distância cultural vem dominando a área de estudos transculturais há mais de quatro décadas por meio de uma visão centrada, sobretudo, no interesse econômico e nas diferenças culturais entre países. O uso dessa metáfora se fundamenta em epistemologia positivista e adota lentes de uma visão estreita; embora, paradoxalmente, seja aplicada à área internacional. O objetivo deste artigo é problematizar os argumentos de Shenkar (2001; 2008) e Luo e Shenkar (2007), segundo os quais a metáfora de "distância" não é apropriada para compreensão, descrição e análise do impacto da questão cultural em negócios internacionais. Propõe-se, aqui, sua substituição pela metáfora da "fricção cultural", que captura de forma mais legítima a essência das questões transculturais aplicadas aos fenômenos em negócios internacionais.

Palavras-chave: Distância cultural. Fricção cultural. Negócios internacionais. Estudos transculturais.

\begin{abstract}
The metaphor of cultural distance has dominated the cross-cultural studies area for over four decades through a vision focused, mainly, on economic interest and cultural differences between countries. The use of this metaphor is grounded on positivist epistemology and adopts lenses of a narrow view; although, paradoxically, it is applied to the international area. This paper aims to problematize the arguments of Shenkar $(2001,2008)$ and Luo and Shenkar (2007), according to whom the metaphor of "distance" is not appropriate for understanding, describing, and analyzing the cultural issue impact on international business. One proposes, here, its replacement by the metaphor of "cultural friction", which captures in a more legitimate way the essence of the cross-cultural issues applied to phenomena in international business.
\end{abstract}

Keywords: Cultural distance. Cultural friction. International business. Cross-cultural studies.

\section{Introdução}

É possível afirmar que a perspectiva da "distância cultural" é uma das mais conhecidas e aceitas na área de negócios internacionais (NI). A possibilidade de mensurar as diferenças das culturas entre nações foi

Artigo submetido em 14 de novembro de 2012 e aceito para publicação em 05 de março de 2013.

${ }^{1}$ Doutoranda em administração pela Fundação Getulio Vargas/EBAPE. Endereço: Rua Mário Pederneiras, 4, Apt. 301, Humaitá, CEP 22261-020, Rio de Janeiro - RJ, Brasil. E-mail: anacelano@gmail.com.

${ }^{2}$ Professora do Programa de Pós-Graduação em Administração da UNIGRANRIO. Endereço: Rua da Lapa, 86 - 9‥ Andar, Lapa, CEP 20021-180, Rio de Janeiro - RJ, Brasil. E-mail: almguedes@gmail.com. 
disseminada pelos estudos de Kogut e Singh (1988) e de Hofstede (1980,1991), autor que trabalhou ainda as dimensões culturais de distância ao poder, fuga de incertezas, individualidade e masculinidade. Vale notar que este conceito desenvolve-se nas últimas quatro décadas centrado no interesse econômico em diferentes culturas no âmbito da globalização (HYMER, 1976).

Assim, a metáfora da "distância" interessou a priori diretamente aos economistas (BECKERMAN, 1956) para, em seguida, ser utilizada por outras disciplinas, como gestão internacional (JOHANSON e WIEDERSHEIM-PAUL, 1975; JOHANSON e VAHLNE, 1977), em um entendimento de que não haveria apenas uma distância geográfica entre países, mas outros padrões possíveis para a contraposição das diferenças.

Neste recorte temporal, a aceitação massiva e incondicional da metáfora da distância cultural foi apoiada pela prevalência de uma epistemologia positivista e com visão estreita baseada em teorias como as de custos de transação (SHENKAR et al., 2008).

Assim, formou-se no campo de estudos internacionais e transculturais, por meio da metáfora da "distância cultural", o caminho natural para as pesquisas relacionadas com a entrada de organizações em mercados estrangeiros, fusões, aquisições internacionais, negociações e estabelecimento de alianças globais.

Esta metáfora mostrou-se tão poderosa e enraizada que se multiplicou em novas e várias propostas teóricas como "distância do conhecimento" (FARJOUN, 1998), "distância institucional" (KOSTOVA, 1999) e "distância tecnológica" (VASSOLO, ANAND e FOLTA, 2004). Como se pode notar, todas essas propostas baseiam-se na metáfora e no conceito de "distância".

Para melhor compreender esta perspectiva, se poderia recorrer a um exemplo hipotético: vários participantes originários de diferentes países realizariam, em um país estranho, um encontro em uma sala de aula de um programa internacional e multicultural de educação em gestão. Nesta situação, diante de um trabalho a ser executado em sala, que envolvesse questões locais particulares, as compreensões de um indiano e de um norte-americano seriam diferentes e baseadas em suas respectivas culturas. Mas, nesse caso, não seria a diferença, ou a "distância" entre as visões, um parâmetro isolado e que representaria o interesse final da atividade, pois, se cada um deles permanecesse preso a suas perspectivas culturais, não haveria nenhum tipo de negociação, cada um permaneceria distante do outro e não ocorreria nenhum aprendizado coletivo com a experiência. Situação muito semelhante, porém mais contundente, aconteceria se, em uma ilha deserta, estivessem um indiano, um norte-americano e um boi. Nesta ilha não haveria alimentos nem recursos que pudessem ser utilizados para a sua obtenção. A questão da distância cultural serviria para entender o conflito iminente e o impasse estabelecido uma vez que seria inaceitável para o indiano alimentar-se do boi, animal sagrado em sua cultura, e absurdo para o norte-americano não fazê-lo, arriscando-se a morrer de fome. A "distância cultural", neste caso, parece se destacar, e torna-se sinônimo de diferença entre os participantes envolvidos no impasse.

Shenkar $(2001,2007,2008)$ chama a atenção para que esta perspectiva de "distância" pode não ser a metáfora mais apropriada à compreensão, descrição e análise do impacto da questão cultural em NI. Propõe, assim, uma metáfora mais adequada, que mude o paradigma dominante e possa melhor capturar a essência das questões transculturais aplicadas aos fenômenos em NI, qual seja, a substituição de "distância" por "fricção".

Neste ensaio teórico, a proposta é revisitar o trabalho de Shenkar $(2001,2007,2008)$ em sua crítica ao conceito de "distância cultural" e, no que se refere à construção de sua nova metáfora de "fricção cultural", realizar um enquadramento teórico e o delineamento de uma nova perspectiva de pesquisa no campo de negócios internacionais. Desta maneira tem-se por objetivo contribuir promovendo reflexão e mobilização em relação a este novo caminho proposto. 
Na primeira etapa deste trabalho será apresentada uma discussão sobre o uso de metáforas na pesquisa organizacional, problematizando especificamente a metáfora de "distância cultural", sua história, aplicações e implicações no campo de NI.

Na sequência, expõe-se a metáfora, proposta por Shenkar (2001, 2007, 2008), de "fricção cultural" como substituta, com melhor poder explicativo do fenômeno, e que incorpora uma perspectiva de realização de encontro cultural e da aceitação de aspectos de poder e hierarquia.

Assim este trabalho pretende descrever como Shenkar $(2001,2007,2008)$ usa a fricção cultural como plataforma de estudo da questão dos encontros culturais em contextos habituais como os de investimento externo direto e como esta metáfora possibilita uma melhor compreensão geral do fenômeno uma vez que se liberta das amarras econômicas e vislumbra a possibilidade de um aprofundamento nas questões sociais em sua dinâmica relacional e em seu poder transformador. Em seguida, as considerações finais.

\section{As Metáforas nos Estudos Organizacionais}

Na medida em que, neste ensaio, se propõe apresentar e discutir a substituição da metáfora de "distância cultural" pela metáfora de "fricção cultural" aventada por Shenkar, Luo e Yeheskel (2008), é justo que se estabeleça uma base teórica para a melhor compreensão do uso de metáforas nos estudos organizacionais.

As metáforas são vistas como um instrumento para a ciência social (KAPLAN, 1964) e também para a pesquisa organizacional (MORGAN, 1980; ALVESSON, 1993). De acordo com Lakoff e Johnson, "[...] a essência da metáfora é compreender e expressar uma coisa em termos de outra" $(1980$, p. 5). Metáforas podem representar uma ajuda eficaz para a pesquisa; como notou Morgan, a "[...] metáfora nos encoraja a pensar e a agir de novas maneiras" (1997, p. 351), expandindo horizontes e criando novas possibilidades de raciocínio.

No entanto, existe uma crítica ao uso das metáforas que não deve ser desprezada e indica suas possíveis implicações negativas. Segundo Pinder e Bourgeois (1982), as metáforas podem afastar os acadêmicos de suas áreas de pesquisa criando um distanciamento e uma possibilidade de perda de conhecimento.

Cornelissen $(2004,2005)$ aponta que, para as teorias organizacionais, as metáforas são mais utilizadas em modelos comparativos que fazem uso de atributos preexistentes. Negligencia-se, desta forma, um esforço mais consistente para a criação de novos significados.

Ainda assim, podemos aceitar que a metáfora é “[...] uma forma estrutural básica de experiência através da qual os seres humanos se engajam, organizam e compreendem seu mundo" (MORGAN, 1983, p. 601). Cabe ressaltar que o uso da metáfora pode ser bastante útil no campo de NI, no qual a diversidade de circunstâncias e significados está em destaque. No entanto, dada a complexidade e a intangibilidade do ambiente internacional, metáforas podem servir como substitutos de uma realidade de difícil observação e aumentar as chances de uma supersimplificação (SHENKAR, 2007, 2008).

De acordo com Morgan e Smircich (1980), a escolha das metáforas reflete pressupostos ontológicos da natureza humana e, nestas escolhas, escondem-se tentativas de mitigar estranhezas e diferenças contidas e pronunciadas em questões internacionais.

Shenkar (2008) não condena o uso de metáforas aplicado ao campo de NI, mas sugere parcimônia e análise em sua utilização, visto que pode limitar a gama de experiências e a possibilidade da construção social de novos significados. Principalmente no contexto internacional, as conclusões precipitadas ou prematuramente simplificadas pela utilização de lentes limitadoras podem restringir seriamente a criação de novos conhecimentos e a compreensão de novos fenômenos que tendem a ficar congelados em significados estáticos pelo uso de metáforas que se estendem além de seus limites e de seu tempo (SHENKAR, 2008). 


\section{Os paradigmas da área de estudos internacionais em gestão}

Para efeito de contextualização do tema proposto dentro da literatura do campo internacional, Boddewyn (1997, 1999) abre a discussão sobre os paradigmas da pesquisa aplicada à área de negócios e à gestão internacional e reforça que o termo "internacional" significa ultrapassar as fronteiras nacionais. Mas o que isso significa para os negócios e mais especificamente para a gestão? Boddewyn (1997) sugere que o propósito analítico de se colocar o termo "negócio" antes da palavra "internacional" é acentuar o fato de que o negócio ocorre em um ambiente de dimensões econômicas, socioculturais e políticas distintas e que tais dimensões têm influência significativa em sua condução. Isto quer dizer que o ambiente no qual o negócio é conduzido varia entre países, o que é suficientemente importante para demandar mudanças nas práticas negociais, se não nas próprias teorias de negócios (NEHRT, TRUITT e WRIGHT, 1970; BODDEWYN, 1999).

Desta forma, a pesquisa neste campo deve contemplar múltiplos níveis de análise, que, de acordo com Guedes (2005), propiciam à pesquisa internacional uma ampliação do escopo da investigação e a exigência de uma abordagem interdisciplinar.

Os três paradigmas em Negócios Internacionais (BODDEWYN, 1997) - descritos a seguir - fornecem três diferentes enquadramentos para os estudos da gestão. Ademais, por meio deles, o significado analítico ligado à palavra "internacional" fornece suporte para se acreditar que a pesquisa em gestão relacionada à cultura é limitada (MARTINEZ e TOYNE, 2000). Se estes paradigmas forem relacionados com a pesquisa internacional, podem-se encontrar questões como as levantados a seguir.

Paradigma da extensão: leva em consideração a universalidade dos conceitos de gestão desenvolvidos com base na perspectiva dominante dos Estados Unidos e que são automaticamente internacionalizados e transpostos a outras realidades e países. Neste caso, pode-se indagar se a prática da gestão não variaria conforme o local em virtude das diferenças ambientais, como, por exemplo, diferenças culturais, econômicas, históricas, legais e sociais. As teorias de gestão ligadas à cultura teriam seu poder explicativo limitado por estas diferenças? Em caso afirmativo, por que e como? (MARTINEZ e TOYNE, 2000).

Paradigma cross-border ou da gestão além-fronteiras: detém-se nas questões de gestão em vários países, sem que haja generalização. Neste caso podem-se levantar discussões a respeito de a operação simultânea em dois ou mais lugares com diferenças ambientais resultarem em variação das práticas de gestão. As teorias de gestão relacionadas a temas além-fronteiras teriam poder de explicação limitado pela necessidade de gerir a diversidade ambiental? São necessárias novas teorias para explicar a gestão da diversidade ambiental? (MARTINEZ e TOYNE, 2000).

Paradigma emergente de interação: tenta combinar e compreender processos múltiplos e distintos que interagem na gestão internacional. Neste caso, pode-se questionar se a experiência obtida com a prática da gestão em ambientes internacionais diversos é capaz de moldá-la e torná-la adequada tanto no país de origem como no país anfitrião. As teorias de gestão sobre diferenças culturais podem explicar estas mudanças e seu processo de transformação em empresas e países? Se não, por quê? São necessárias novas teorias para explicar as mudanças em gestão que ocorrem por conta da interação entre dois ou mais distintos processos de negócios? (MARTINEZ e TOYNE, 2000).

Desta forma, ao considerar e refletir sobre os argumentos propostos por Martinez e Toyne (2000), observa-se a necessidade de uma revisão sobre os propósitos e as implicações em pesquisas internacionais. Isto porque, quando se trata de Gestão Internacional, a palavra "internacional" tem o objetivo de acentuar o fato de que o meio ambiente onde ocorre a gestão pode ter efeito sobre a sua prática. Ao mesmo tempo, o ambiente não é necessariamente visto como algo que tenha efeito sobre as teorias de administração. Assim, quando há necessidade de relacionar a pesquisa em administração com as questões internacionais, isto ocorre como uma forma de internacionalizar ou adaptar a ciência normal (KUHN, 1970), que inclui todas as perspectivas 
reconhecidas de pesquisa em administração. Além disso, esta forma de investigação em gestão pode resultar na modificação, ou até na rejeição, de teorias de gestão ligadas a questões culturais.

A palavra "internacional" também acentua aspectos distintos da gestão presentes nas organizações que operam simultaneamente em dois ou mais ambientes, logicamente diferentes. Neste ponto a pesquisa em gestão internacional enfrenta desafios à compreensão destes fenômenos e dos relacionamentos que ocorrem dentro das situações que conectam diferentes culturas (JACK e WESTWOOD, 2009).

E, ainda, a palavra "internacional" é normalmente utilizada para reforçar um único aspecto de gestão, que usualmente traz em sua compreensão aspectos de dominação e poder. Isto acontece quando, em geral, uma organização internacionaliza sua gestão levando para outros ambientes suas práticas e procura aplicar, no máximo, uma adaptação da gestão que leve em conta certas diferenças culturais, interpretadas, por sua vez, pelas lentes do país de origem da empresa (JACK e WESTWOOD, 2009). Esta prática não leva em consideração a interação entre as partes envolvidas e as necessidades criadas por meio desta conexão.

Martinez e Toyne (2000) ainda pontuam que a pesquisa focada na área internacional baseada em teorias de múltiplos níveis de análise, interdisciplinaridade metodológica e realizada habitualmente por equipes multiculturais ou multinacionais precisam desenvolver um campo de estudo da gestão que tenha um escopo verdadeiramente internacional. $\mathrm{O}$ crescimento destes estudos em gestão internacional fora do domínio dos Estados Unidos pode ajudar a trazer novas perspectivas ao campo.

Na próxima sessão vamos tratar da metáfora de distância cultural como a metáfora dominante e escolhida para dar conta das questões de diferenças culturais no campo de NI.

\section{A metáfora de "distância cultural"}

O conhecimento e a penetração de novos mercados, assim como o próprio desenvolvimento internacional, estão entre os principais interesses das organizações, principalmente após a ocorrência do fenômeno da globalização da economia (JACK e WESTWOOD, 2009).

Essa política econômica de investimentos que tende a se globalizar cada vez mais intensamente leva a que as empresas confrontem-se mais com a distância entre seu país de origem e o país onde se estabelecerá, seja de que forma for. Assim, a metáfora da "distância" aparece na literatura com o crescente interesse no relacionamento econômico de diferentes culturas no âmbito da globalização (HYMER, 1976).

Desse modo, a metáfora da "distância" interessou a priori diretamente aos economistas (BECKERMAN, 1956), para, em seguida, ser utilizada por disciplinas outras como gestão internacional (JOHANSON e WIEDERSHEIM-PAUL, 1975; JOHANSON e VAHLNE, 1977). Seu propósito era a mensuração da "distância" entre países, entendendo-se que não haveria apenas uma distância geográfica, mas outros padrões possíveis para a contraposição de diferenças.

O primeiro termo utilizado que ultrapassava a fronteira da distância puramente geográfica e se aproximava da mensuração do que seria uma "distância cultural" foi o de "distância psicológica". Ele surgiu no modelo de Uppsala, também conhecido como Escola Escandinava (JOHANSON e WIEDERSHEIM-PAUL, 1975). Segundo este modelo, uma empresa normalmente privilegia seus investimentos em países onde existe uma tênue distância psicológica, e dá prosseguimento a seus investimentos utilizando uma escala que a leve em consideração.

Em sequencia ao construto de distância psicológica vieram os trabalhos de Hofstede $(1980,1991)$, Kogut e Singh (1988), que utilizaram em seu lugar a metáfora da distância cultural. Para estes autores, a distância cultural entre os países podia ser medida por intermédio de diferentes dimensões, tais como: distância 
hierárquica, ou distância ao poder; individualismo ou coletivismo; masculinidade ou feminilidade; grau de insegurança ou medo das incertezas; e por último a orientação do país para soluções de longo ou curto prazo.

No entanto, se a distância cultural foi aplicada a um conjunto de propósitos da gestão, como a estratégia, os recursos humanos ou o comportamento organizacional, foi também e principalmente utilizada para a análise dos Investimentos Diretos ao Estrangeiro (IDE), com o objetivo de prever e determinar seus fatores de sucesso. Por razões como limitação ao viés econômico e aplicação metodológica de cunho generalizável diante de um mundo cada vez mais diverso e multicultural, estas teorias vêm sendo fortemente criticadas (SHENKAR, 2001; JACK, CALÁS, NKOMO et al., 2008).

De acordo com Cox (2007), o paradigma científico internacional mudou, o mundo como "dado" foi substituído pelo mundo que vive um processo evolutivo e no qual a única certeza sobre o futuro é que ele não vai ser igual ao passado. Vive-se agora o desafio não apenas de entender a nova dinâmica de "autoorganização" humana, mas a sua participação nesse processo.

Segundo Shenkar (2001, 2008), o conceito inserido na metáfora de "distância" comporta implicações que jamais foram estabelecidas. A ideia de simetria, por exemplo, sugeriria que, de fato, a distância entre duas culturas fossem sempre equânimes e justas e, não, distorcidas por jogos de poder ou por relações que estabelecem a hegemonia e o domínio entre diferentes países e partes do mundo. As culturas não representam sempre os mesmo papéis, com as mesmas "distâncias" e as mesmas perspectivas. A visão do investidor será a mesma do país que receberá seu investimento? É correto dizer que suas perspectivas se igualam? Desta forma, com esta metáfora, parece não se levar em conta a natureza da interação no tempo do que seja a própria "distância cultural" entre diferentes culturas, o que reduz sua aplicação à questão de que, quanto mais diferente ou distante uma cultura da outra, haverá menos investimentos dos recursos de uma empresa. Ou seja, trata-se de uma questão presa ao IDE (NKOMO e COX, 2006).

Assim se estabeleceu um padrão dominante, sem que se provasse que é capaz de ligar de forma linear a distância cultural, o investimento direto (IDE), o modo de entrada de uma empresa no estrangeiro e sua performance. Deste modo, quanto mais diferentes as culturas, mais tardio o investimento na estratégia de internacionalização do negócio, que será menos uma estratégia de controle e estará mais sujeita ao fracasso. As empresas podem, também, apresentar dificuldade de adaptação a uma cultura próxima pelo fato de ignorar os traços de diferença cultural ao partir do pressuposto de que distâncias pequenas não existem ou nem mesmo precisam ser consideradas (ADLER, 1981; BREWSTER, 1995; O'GRADY e LANE, 1996). Enfim, a base segundo a qual a distância cultural tem um impacto direto sobre a forma do IDE, sua forma de entrada no novo país e sua performance, tende a ocultar outros fatores que não fazem parte desta teoria.

Cabe notar que o uso da perspectiva da distância cultural, tão focada nas diferenças, funciona apenas no âmbito internacional, sendo ignoradas diferenças locais ou regionais, ou mesmo diferenças culturais presentes em uma mesma organização. Em virtude disso, empresas que atuam em territórios nacionais (grandes ou pequenos) e contam em seus quadros com uma força de trabalho multicultural são consideradas entidades homogêneas (HOFSTEDE et al., 1990).

De forma contrária, Laurent (1986), Weber, Shenkar e Raveh (1996) levam em conta que a cultura organizacional pode influenciar comportamentos e crenças relativas a uma cultura nacional, amplificando a complexidade dos níveis de análise envolvidos no tema. O mesmo conceito de homogeneidade aplicado a um país pode ser igualmente falso por desconsiderar as possíveis variações regionais ou étnicas e remeterá a dificuldades de compreensão devido à complexidade envolvida nesta questão (MARIOTTI e PISCITELLO, 1995). Enfim, é necessário refletir sobre as diferentes dimensões da metáfora da distância cultural, principalmente quanto a seus impactos e aplicações além do IDE (HAMEL, DOZ e PRAHALAD, 1989; SHANE, 1992; DICKSON e WEAVER, 1997; NKOMO e COX, 2006; JACK, CALÁS, NKOMO et al., 2008; SHENKAR, 2001, 2007, 2008). 


\section{A metáfora da fricção cultural}

O conceito padronizado e estabelecido da distância cultural sedimentou-se nos princípios da expansão dos mercados e, de uma maneira geral, foi útil para criar teorias "livres de contexto" (JACK, CALÁS, NKOMO et al., 2008). Shenkar (2001) assume que muitos estudiosos basearam suas teorias sobre a existência de uma suposta homogeneidade cultural dentro de um país ou local específico (HOFSTEDE, 1980; KOGUT e SINGH, 1988; BENITO e GRISPUD, 1992; FLETCHER e BOHN, 1998). O autor faz uma crítica dessas teorias, em razão de muitos países serem formados por diferentes etnias ou regionalmente desenvolvidos por diferentes valores e tradições culturais (O'GRADY e LANE, 1996; JACK, CALÁS, NKOMO et al., 2008).

Pode haver uma ilusão em tentativas de encurtar a distância pela proximidade cultural ou geográfica dos países (SHENKAR, 2001; LUO e SHENKAR, 2007). Ao se aplicar o construto da distância cultural, por exemplo, países como Brasil e Argentina ou Estados Unidos e Canadá podem parecer mais próximos do que o são se vistos por essas lentes. Além disso, o comprometimento da globalização diz respeito apenas a trazer a diversidade de uma forma bastante fragmentada, principalmente para dentro das organizações, favorecendo a análise individual do fenômeno apenas com as considerações críticas sobre as influências externas e coletivas.

De acordo com Santos (2006) a ideia de globalização como um fenômeno linear, homogeneizador e irreversível é falsa, porém prevalece como central na vida cotidiana atual. Aparentemente transparente e sem muitas complexidades, tal ideia obscurece mais do que esclarece o que se passa hoje no mundo. Observandose de uma perspectiva diferente, o que a ideia de globalização mascara é tão importante que, longe de apresentar uma inocente transparência e simplicidade, deve ser considerada como um movimento ideológico e político.

Nas últimas três décadas, as interações transnacionais conheceram uma intensificação dramática nos sistemas de produção e em transferências financeiras para a disseminação mundial de informações, conhecimentos e imagens por intermédio dos meios de comunicação ou movimentos em massa de pessoas querem como turistas, como trabalhadores migrantes ou refugiados. A extraordinária amplitude e profundidade destas interações transnacionais levaram cientistas sociais e políticos a vê-las como uma ruptura com as formas anteriores de interação além-fronteiras, um novo fenômeno denominado "globalização". De acordo com Santos (2006), hoje o termo "global" é usado para referir-se tanto aos processos como aos resultados da globalização.

De acordo com Shenkar (2008, p. 905), "[...] a metáfora da distância cultural domina a investigação internacional de gestão, promovendo uma visão estéril onde antecedentes estáticos na forma de diferenças artificialmente construídas servem como lente através da qual a cultura dominante é vista e seu impacto avaliado". O autor propõe, então, uma nova metáfora, a de "fricção cultural", que adota uma abordagem construcionista social. Esta proposta do autor baseia-se no encontro real dos sistemas culturais dentro de um contexto de poder e de conflito potencial entre uma empresa multinacional e seus diversos públicos no país de acolhimento. Defende que a nova metáfora, aplicada a fenômenos de negócios internacionais, pode captar melhor a essência do encontro intercultural. É especialmente no campo internacional, em que existe um mosaico dinâmico e complexo do meio ambiente, que várias lentes disciplinares são necessárias para evitar confundir uma porção do fenômeno com o todo (ROBERTS e BOYACIGILLER, 1984).

No Dicionário Oxford de Inglês, o atrito é definido como "a ação do atrito e fricção", e secundariamente como "a friç̧ão de um corpo contra o outro"; "A resistência física e mecânica, que qualquer organismo se encontra com em que se move sobre outro corpo 'e' o chocante e o conflito de opiniões, ao contrário, temperamentos compreendendo conotações de tensão e luta com a natureza do encontro". Coser (1956, p. 23) observa que o conflito não é necessariamente "disfuncional e perturbador" (ver também MORGAN, 1997), reconhecendo que se trata de um encontro de interesses divergentes. 
Substituir "distância" por "fricção" denota mudar a ênfase das diferenças abstratas em direção ao contato entre as entidades específicas, para as suas preocupações partidárias. Implica, também, deixar para trás uma visão ingênua da globalização como uma era na qual as pessoas, capitais, bens e ideias movem-se sem impedimento e as barreiras à interação não são onipresentes (TSING, 2005). Com a lente de atrito, a cultura passa a ser vista como algo criado e recriado (JELINEK, SMIRCICH e HIRSCH, 1983) por atores inseridos em identidades organizacionais e nacionais (SCHNEIDER, 1988; WEBER, SHENKAR e RAVEH, 1996), com divergentes recursos e interesses e que detêm o poder assimétrico e posição hierárquica (BURRELL e MORGAN, 1979), que estão envolvidos em uma troca permanente, a qual consiste de uma cadeia de respostas e contra respostas (HOMANS, 1950).

Na metáfora de atrito ou fricção cultural existe a real possibilidade de contemplar a divergência fundamental de interesses entre uma multinacional e o país de acolhimento, pois as metas nacionais, econômicas, sociais definidas pelos nativos são fundamentalmente diferentes dos objetivos das corporações multinacionais (POYNTER, 1985; GROSSE, 1996; SHENKAR, 2008).

Alguns conceitos básicos da metáfora de fricção cultural proposta por Shenkar, Luo e Yeheskel (2008) são representados pelo "ponto de contato", onde as entidades se cruzam para produzir atrito cultural, e pela "troca cultural", por meio da qual os bens culturais são negociados e trocados.

O ponto de contato mostra, de uma perspectiva de atrito, que, em vez de se olhar para o modo de entrada da maneira tradicional, como um produto das diferenças culturais, vê-se como algo, pelo menos parcialmente, determinado pelo poder, que, por sua vez, influencia o nível e a natureza de atrito cultural. Desta perspectiva, é importante notar que as estruturas representam uma tentativa de dominação cultural e centralização do poder, bem como um esforço para aumentar a eficiência organizacional (LUO e SHENKAR, 2007).

A troca que ocorre durante o encontro cultural pode ser regulada por empresas mediante recursos humanos e ações de comunicação interna. Empresas transnacionais geralmente contratam os executivos culturalmente sensíveis e/ou com conhecimento cultural sobre o país anfitrião (SPREITZER, MCCALL e MAHONEY, 1997; SHENKAR, LUO e YEHESKEL, 2008). A cultura da empresa pode ser vista como um meio de controle, uma vez que pode substituir, em algum nível, sistemas de cultura nacionais. Luo e Shenkar (2007) e Laurent (1986) postulam que a fricção ou o atrito potencial entre os sistemas culturais podem realmente aumentar em virtude de uma forte cultura corporativa. As comunicações internas são geralmente vistas como um processo particular eficiente de se comunicar e difundir uma cultura corporativa. O ponto de contato é importante para compreender a natureza do encontro cultural.

\section{Discussão Final}

Este ensaio teve como propósito discutir a mudança de paradigma envolvida na pesquisa de âmbito internacional, principalmente aquela relacionada a temas transculturais. Para tanto, analisou-se a utilização corrente da metáfora da distância cultural - que, no atual contexto do mundo globalizado, pode não ser a melhor opção para a compreensão e análise dos fenômenos deste campo - bem como se apresentou uma nova metáfora, a de fricção cultural, proposta por Shenkar $(2001,2008)$ e Luo e Shenkar (2007).

É importante salientar, como dito anteriormente, que metáforas, teorias e métodos podem estabelecer um relacionamento simbiótico. A aceitação incondicional da metáfora da distância cultural vem sendo apoiada, em virtude da prevalência de uma epistemologia positivista e com visão estreita, na maioria dos estudos realizados na área de negócios internacionais (SHENKAR, 2008; JACK e WESTWOOD, 2009).

Já a metáfora de fricção cultural, proposta por Shenkar (2008) e Luo e Shenkar (2007), permite aos pesquisadores uma investigação mais aprofundada sobre os relacionamentos entre culturas com suas consequências epistemológicas. Lançando luz sobre o fenômeno do contato entre partes que se relacionam e 
não deixando de lado a questão do poder envolvido e de suas assimetrias, a "fricção" parece oferecer uma forma mais ampla de apreciação da complexidade e da compreensão dialética envolvida na natureza das interações culturais.

Desta forma, causa certa surpresa que, mesmo alguns anos após a publicação dos artigos de Shenkar (2008) e Luo e Shenkar (2007), ainda não exista no meio acadêmico um número expressivo de pesquisas em estudos transculturais que utilizem a nova metáfora proposta, principalmente entre trabalhos empíricos na área de negócios internacionais.

No caso hipotético, apresentado na introdução deste artigo, de um norte-americano e um indiano - seja em uma sala de aula, seja em uma ilha deserta - diante da necessidade de solução de um impasse ou de interação, se a metáfora da distância cultural fosse substituída pela metáfora da fricção cultural, haveria mais ênfase na solução deste impasse, em lugar de uma concentração de esforços para entender e justificar a motivação do conflito.

No uso da metáfora de fricção cultural há talvez um interesse mais legítimo e produtivo na compreensão de fenômenos complexos envolvidos nas questões transculturais. Afinal, enquanto o norte-americano e o indiano estivessem centrados em suas diferenças, ou distâncias inconciliáveis, e o foco estivesse na defesa das diferentes perspectivas, haveria um atraso ou mesmo a impossibilidade de se alcançar um resultado ou um "atrito" positivo que pudesse beneficiar ambas as partes.

Assim, Shenkar (2008) defende que a metáfora da fricção cultural permite uma melhor compreensão e solução das situações que parecem levar a impasses. De fato, se considerado o exemplo mencionado, a ideia da fricção subentende um contato, uma interação das diferentes culturas e perspectivas.

Por vezes a ideia da fricção pode remeter a uma imagem de conflito, o que não significa que a interação não seja benéfica à relação. De fato, um conflito ou um impasse podem ser resolvidos por meio de um diálogo possível na medida em que ambas as partes se sentem próximas o suficiente para estabelecer um processo comunicativo. Esta é uma questão importante uma vez que a metáfora da distância cultural sugere a ausência de contato e a dificuldade de comunicação (TSING, 2005; LUO e SHENKAR, 2007; SHENKAR, 2008).

No exemplo hipotético utilizado neste artigo, será por meio da interação ou da fricção cultural que os dois personagens poderão estabelecer uma comunicação, estabelecer regras e se adaptar um ao outro, inclusive negociando concessões e buscando novas soluções fora da figura do boi.

A metáfora da fricção cultural permite imaginar que ao final eles encontrariam uma solução para o impasse, que a comunicação e o entendimento de suas diferenças funcionariam em um mesmo ambiente, sendo determinantes para um desfecho. No entanto, se a leitura ocorresse apenas por meio da metáfora da distância cultural, na cena imaginada cada um dos personagens estaria só, em lados opostos da ilha, realmente "distantes". A solução se tornaria inviável, afinal cada um dos indivíduos estaria apenas defendendo o seu ponto de vista, a sua posição, a sua diferença, a sua cultura como única perspectiva válida.

\section{Referências}

ADLER, N. J. Re-entry: managing cross-cultural transitions. Group and Organizations Studies, v. 6, n. 3, p. 341-356, 1981.

ALVESSON, M. The play of metaphor. In: HASSARD J.; PARKER M. (Eds.), Postmodernism and organizations. London: Sage, 1993. p. 114-131.

BECKERMANN, W. Distance and the pattern of intra-European trade. Review of Economics and Statistics, v. 38, n. 1, p. 31-40, 1956. 
BENITO, G. R. G.; GRIPSRUD, G. The expansion of foreign direct investments: discrete rational location choices or a cultural learning process? Journal of International Business Studies, v. 23, n. 3, p. 461-476, 1992.

BODDEWYN, J. J. The conceptual domain of international business: territory, boundaries, and levels. In: TOYNE, B., NIGH, D. (Eds.), International business: an emerging vision. Carolina do Sul: University of South Carolina Press, Columbia, 1997. p. 50-61.

The domain of international management. Journal International Management, v. 5, n. 1, p. 3-14. 1999.

BREWSTER, C. Effective expatriate training. In: SELMER, J. (Ed.), Expatriate Management: new ideas for international business. Westport, CN: Quorum, 1995.

BURRELL, G.; MORGAN, G. Sociological paradigms and organizational analysis. London: Heinemann, 1979.

CORNELISSEN, J. P. What are we playing at? Theatre, organization, and the use of metaphor. Organization Studies, v. 25 , n. 5 , p. 705-726, 2004

2005.

. Beyond compare: metaphor in organization theory. Academy of Management Review, v. 30, n. 4, p. 751-764,

COSER, L. A. The functions of social conflict. New York: Free Press, 1956.

COX, R. W. 'The international' in Evolution. Millenium. Journal of International Studies, v. 35, n. 3, p. 513-527, 2007.

DICKSON, P. H.; WEAVER, K. M. Environmental determinants and individual level moderator of alliance use. Academy of Management Journal, v. 40, n. 2, p. 404-425, 1997.

FARJOUN, M. The independent and joint effects of the skill and physical bases of relatedness in diversification. Strategic Management Journal, v. 19, n. 7, p. 611-630, 1998.

FLETCHER, R.; BOHN, J. The impact of psychic distance on the internationalization of the Australian firm. Journal of Global Marketing, v. 12, n. 2, p. 47-68, 1998.

GROSSE, R. The bargaining relationship between foreign MNEs and host governments in Latin America. The International Trade Journal, v. 10, n. 4, p. 467-499, 1996.

GUEDES, A. L. M. Pesquisa internacional em gestão: abordagem interdisciplinar com múltiplos níveis de análise. In: Pesquisa Qualitativa em Administração. Rio de Janeiro: FGV Editora, 2005.

HAMEL, G.; DOZ, Y.L.; PRAHALAD, C.K. Collaborate with your competitors and win. Harvard Business Review, v. 6, n. 1, p. 133-139, 1989.

HOFSTEDE, G. Culture's consequences: international differences in work-related values. Beverly Hills, CA: Sage, 1980.

Cultures and Organizations: software of the mind. London: Mc Graw - Hill, 1991.

et al. Measuring Organizational cultures: a qualitative and quantitative study across twenty cases. Administrative science quarterly, v. 35, n. 2, p. 386-316, 1990.

HOMANS, G. The human group. New York: Harcourt Brace, 1950.

HYMER, S. H. The international operations of national firms: a study of direct foreign investment. Cambridge, MA: MIT Press, 1960/1976.

JACK, G. A. et al. Critique and international management: an uneasy relationship? Academy of Management Review, v. 33, n. 4, p. 870-884, 2008. 
JACK, G.; WESTWOOD, R. International and Cross-Cultural Management Studies: A Postcolonial Reading. Basingstoke: Palgrave Macmillan, 2009.

JELINEK, M.; SMIRCICH, L.; HIRSCH, P. A code of many colors. Administrative Science Quarterly, v. 28, n. 3, p. 331-338, 1983.

JOHANSON, J.; VAHLNE, J. E. The internationalization process of the firm: a model of knowledge development and increasing foreign market commitments. Journal of International Business Studies, v. 8, n. 1, p. 23-32, 1977.

. ; WIEDERSHEIM-PAUL, F. The internationalization of the firm: four swedish cases. Journal of Management Studies, v. 12, n. 3, p. 305-322, 1975.

KAPLAN, A. The logic of inquiry. New York: Chandler, 1964.

KOGUT, B.; SINGH, H. The effect of national culture on the choice of entry mode. Journal of International Business Studies, v. 19, n. 3, p. 411-432, 1988.

KOSTOVA, T. Transnational transfer of strategic organizational practices: a contextual perspective. Academy of Management Review, v. 24, n. 2, p. 308-325, 1999.

KUHN, T. S. The structure of scientific revolutions. Chicago, IL: The University of Chicago Press, 1970.

LAKOFF, G.; JOHNSON, M. Metaphors we live by. Chicago: University of Chicago Press, 1980.

LAURENT, A. The cross cultural puzzle of international human resource management. Human Resource management, v. 25, n. 1, p. 91-102, 1986.

LUO, Y.; SHENKAR, O. Cultural friction in international business: a new theoretical perspective. WPS-MGT-0701, 2007.

. ; __ ; NYAW, M. K. A dual parent perspective on control and performance in international joint ventures: Lessons from a developing economy. Journal of International Business Studies, v. 32, n. 1, p. 41-58, 2001.

MARIOTTI, S.; PISCITELLO, L. Information costs and location of FDIs within the host country: empirical evidence from Italy. Journal of International Business Studies, v. 26, n. 4, p. 815-841, 1995.

MARTINEZ, Z. L.; TOYNE, B. What is international management, and what is its domain? Journal of International Management, v. 6, n. 1, p. 11-28, 2000

MORGAN, G. Paradigms, metaphors, and puzzle solving in organization theory. Administrative Science Quarterly, v. 25, n. 4, p. 605-622, 1980.

More on metaphor: Why we cannot control tropes in administrative science. Administrative Science Quarterly, v. 28, n. 4, p. 601-607, 1983.

Images of organization. Thousand Oaks, CA: Sage, 1997.

1980.

. ; SMIRCICH, L. The case for qualitative research. Academy of Management Review, v. 5, n. 4, p. 491-500,

NEHRT, L.; TRUITT, F.; WRIGHT, R. International business: past, present, and future. Bloomington, IN: Indiana University Graduate School of Business, 1970.

NKOMO, S. M.; COX, T. Diversidade e identidade nas organizações. In: CLEGG, S. R.; HARDY, C.; NORD, W. R. (Eds.). Handbook de Estudos Organizacionais: modelos de análise e novas questões em estudos organizacionais, v. 1. São Paulo: Atlas, 2006. p. 332-358. 
O’GRADY, S.; LANE, H. W. The psychic distance Paradox. Journal of International Business Studies, v. 27, n. 2, p. 309-333, 1996.

PINDER, C. C.; BOURGEOIS, V. W. Controlling tropes in administrative science. Administrative Science Quarterly, v. 27, n. 4, p. 641-652, 1982.

POYNTER, T. A. Multinational enterprises and government intervention. New York: St. Martin's Press, 1985.

ROBERTS, K. H.; BOYACIGILLER, N. A. Cross-national organizational research: the grasp of the blind men. Research in Organizational Behavior, v. 6, n. 3, p. 423-475, 1984.

SANTOS, B. S. Globalizations. Theory Culture Society, v. 23, n. 2-3, p. 393-399, 2006.

SCHNEIDER, S. C. National vs. corporate culture: implications for human resource management. Human Resource Management, v. 27, n. 2, p. 231-246, 1988.

SHANE, S. A. The effect of national cultural differences in perceptions of transaction costs on national differences in the preferences for licensing. Academy of management best papers proceedings, 1992

SHENKAR, O. Cultural distance revisited: towards a more rigorous conceptualization and measurement of cultural differences. Journal of International Business Studies, v. 32, n. 3, p. 519-535, 2001.

. ; LUO, Y.; YEHESKEL, O. From "distance" to "friction": substituting metaphors and redirecting intercultural research. Academy of Management Review, v. 33, n. 4, p. 905-923, 2008.

SPREITZER, G. M.; MCCALL, M. W.; MAHONEY, J. D. Early identification of international executive potential. Journal of Applied Psychology, v. 82, n. 1, p. 6-29, 1997.

TSING, A. L. Friction: an ethnography of global connection. Princeton, NJ: Princeton University Press, 2005.

VASSOLO, R. S.; ANAND, J.; FOLTA, T.B. Non-additivity in portfolios of exploration activities: a real options-based analysis of equity alliances in biotechnology. Strategic Management Journal, v. 25, n. 11, p. 1045-1061, 2004.

WEBER, Y.; SHENKAR, O.; RAVEH, A. National and corporate cultural fit in mergers/acquisitions: an exploratory study. Management Science, v. 42, n. 8, p. 1215-1227, 1996. 